University of Nebraska - Lincoln

DigitalCommons@University of Nebraska - Lincoln

Faculty Publications from the Department of Electrical \& Computer Engineering, Department Electrical and Computer Engineering

2011

\title{
Bearing Fault Detection for Direct-Drive Wind Turbines via Stator Current Spectrum Analysis
}

Xiang Gong

University of Nebraska-Lincoln, xiang.gong@huskers.unl.edu

Wei Qiao

University of Nebraska-Lincoln, wqiao@engr.unl.edu

Follow this and additional works at: https://digitalcommons.unl.edu/electricalengineeringfacpub

Part of the Electrical and Computer Engineering Commons

Gong, Xiang and Qiao, Wei, "Bearing Fault Detection for Direct-Drive Wind Turbines via Stator Current Spectrum Analysis" (2011). Faculty Publications from the Department of Electrical and Computer Engineering. 214.

https://digitalcommons.unl.edu/electricalengineeringfacpub/214

This Article is brought to you for free and open access by the Electrical \& Computer Engineering, Department of at DigitalCommons@University of Nebraska - Lincoln. It has been accepted for inclusion in Faculty Publications from the Department of Electrical and Computer Engineering by an authorized administrator of DigitalCommons@University of Nebraska - Lincoln. 


\section{Bearing Fault Detection for Direct-Drive Wind Turbines via Stator Current Spectrum Analysis}

\author{
Xiang Gong \\ Department of Electrical Engineering \\ University of Nebraska-Lincoln \\ Lincoln, NE 68588-0511 USA \\ xiang.gong@huskers.unl.edu
}

\author{
Wei Qiao \\ Department of Electrical Engineering \\ University of Nebraska-Lincoln \\ Lincoln, NE 68588-0511 USA \\ wqiao@engr.unl.edu
}

\begin{abstract}
Bearing faults constitute a significant portion of all faults in wind turbine generators (WTGs). Current-based bearing fault detection has significant advantages over traditional vibration-based methods in terms of cost, implementation, and system reliability. This paper proposes a method based on stator current power spectral density (PSD) analysis for bearing fault detection of direct-drive WTGs. In the proposed method, appropriate interpolation/up-sampling and down-sampling algorithms are designed to convert the variable fundamental frequency of the stator current to a fixed frequency according to the estimated fundamental speed of the WTG. Consequently, the characteristic frequencies of bearing faults can be clearly identified form the resulting stator current PSD. Experimental results show that the proposed method can effectively detect bearing outer-race and innerrace defects for a direct-drive WTG.
\end{abstract}

\section{INTRODUCTION}

Bearing faults constitute a significant portion of all faults in WTGs. The experience feedback from the wind energy industry corroborates that bearing failure is one of the typical failures in WTGs [1]. It is highly desired to detect the bearing faults and repair or replace the faulted bearing(s) to prevent catastrophic damages of the WTG systems.

Conventional bearing fault detection techniques require additional mechanical sensors and data acquisition equipment to implement [2]. The most commonly used sensors are vibration sensors, such as accelerometers. These sensors are mounted on the surface of WTG components, which are situated on high towers and are difficult to access during WTG operation. Moreover, the sensors and equipment are inevitably subject to failure, which could cause additional problems with system reliability and additional operating and maintenance costs. Current-based (mechanical-sensorless) fault detection techniques do not require additional sensors above those already used for monitoring, control, and protection of the WTG systems. Moreover, current signals are reliable and easily accessible from the ground without intruding the WTGs. Therefore, current-based fault detection techniques have great economic

This work was supported by the U.S. Department of Energy under Grant DE-EE0001366 and the Nebraska Center for Energy Science Research (NCESR). benefits and potential to be adopted by the wind energy industry.

There are some challenges in using current signals for wind turbine bearing fault detection. The characteristic frequency of bearing faults in the stator current of a rotating machine is a function of its shaft rotating speed [3]. As mentioned in [4], [5], since the shaft rotating speed of a WTG usually varies with wind speed, it is a problem to extract the bearing fault information from the non-stationary stator current signals of the WTG. Moreover, WTGs are normally situated on high towers. The vibrations of WTGs and towers inevitably introduce low-frequency interferences into the current signals. Some research [2] has shown that the useful information in current signals for bearing fault detection normally has a low signal-to-noise ratio (SNR), which makes the fault detection difficult.

Several signal processing techniques, including the classical PSD analysis [6], [7], wavelet analysis [5], [8], amplitude modulation (AM)/frequency modulation (FM) demodulation techniques [1], and statistical methods [9], [10], have been used for current-based bearing fault detection of electric machines [6]-[9] or WTGs [1], [5]. The classical PSD analysis can identify different types of bearing faults based on their characteristic frequencies in the stator current signals. However, this capability is only available for stationary stator current signals. Both the wavelet analysis and $\mathrm{AM} / \mathrm{FM}$ demodulation techniques are able to extract bearing fault information from non-stationary stator current signals of a WTG. However, they cannot identify bearing faults or interferences that have close characteristic frequencies.

This paper proposes a novel PSD analysis-based method for bearing fault detection of direct-drive wind turbines using generator stator current signals. The proposed method processes the stator current signals in a way such that the variable characteristic frequencies of bearing faults become a constant value in the PSD of the processed current signals. The proposed method is validated by experimental studies 
for detection of outer-race and inner-race bearing faults of a direct-drive WTG operating at variable-speed conditions.

\section{Characteristic Frequencies of Bearing Faults}

If an outer-race or inner-race bearing fault occurs in an electric machine, mechanical vibrations will appear in the rotating shaft of the machine. These vibrations will result in air gap eccentricity, which subsequently will produce anomalies in the air gap flux density [6]. Furthermore, these vibrations have characteristic frequencies, which are associated with the shaft rotating speed. According to [11], the approximated characteristic frequencies of an outer-race and an inner-race bearing fault in vibration measurements for most bearings with 6 to 12 balls are given by the following two equations, respectively.

$$
\begin{aligned}
f_{o} & =0.4 \cdot N_{b} \cdot f_{r} \\
f_{i} & =0.6 \cdot N_{b} \cdot f_{r}
\end{aligned}
$$

where $f_{o}$ and $f_{i}$ are the characteristic frequencies of the outerrace and inner-race bearing fault in vibration signals, respectively; $N_{b}$ is the number of balls of the bearing; $f_{r}$ is the shaft rotating frequency. Vibration measurements were traditionally used for bearing fault detection.

To apply generator stator current measurements for WTG bearing faults detection, the influence of bearing damage on the stator currents of the wind generator needs to be modeled. The most frequently used model is given in [6] for induction machine bearing fault detection. Reference [3] extended the result in [6] by taking into account the radial movement of the bearing rotor center and load torque variations. The approximated characteristic frequencies of an outer-race and inner-race bearing fault in stator current signals are given below.

$$
\begin{gathered}
F_{\text {outer }}=f_{1} \pm l \cdot f_{o} \\
F_{\text {inner }}=f_{1} \pm f_{r} \pm l \cdot f_{i}
\end{gathered}
$$

where $F_{\text {outer }}$ and $F_{\text {inner }}$ are the characteristic frequencies of the outer-race and inner-race bearing fault in stator current signals, respectively; $f_{r}$ is the shaft rotating frequency; $f_{1}$ is the fundamental frequency of the stator current; usually $f_{1}=$ $p \times f_{r}$ in a direct-drive WTG, where $p$ is the number of pole pairs of the generator; and $l=1,2,3 \ldots$.

Taking a defect on the outer race of a bearing as an example, regular shakes occur when the balls of the bearing pass though the defect along with the rotating shaft of the WTG. Therefore, the frequency of the balls passing though the defect of the outer race is $f_{o}$. The schematic diagram of a bearing with an outer-race defect is shown in Fig. 1, where $I d$ is the diameter of the bore; $O d$ is the outer ring diameter; $B d$ is the diameter of the balls; and $T d$ is the thickness of the outer and inner races of the bearing. When the inner race of the bearing rotates, assume $x$ balls have passed through the outer-race defect, then the distance of a ball passing the inner race is equal to that of the ball passing the outer race:
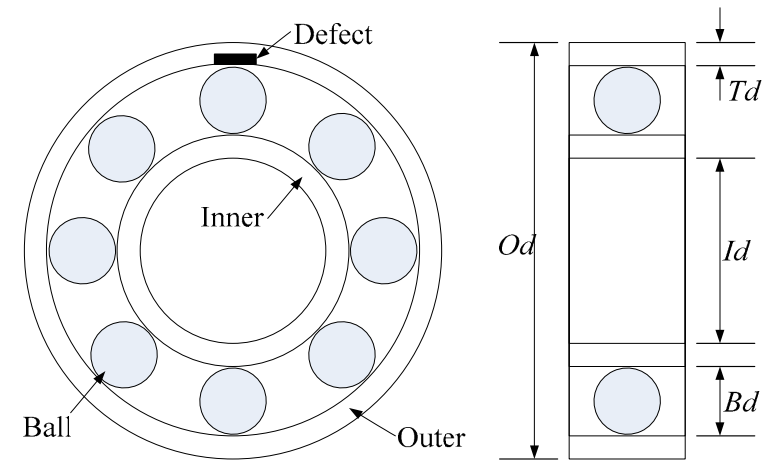

Fig. 1. The schematic diagram of a bearing with an outer-race defect.

$$
2 \pi\left(\frac{I d}{2}+T d\right)\left(1-\frac{x}{N_{b}}\right)=2 \pi\left(\frac{O d}{2}-T d\right) \frac{x}{N_{b}}
$$

Solving for $x$ using (5), then $f_{o}$ can be determined by:

$$
f_{0}=x f_{r}=\frac{I d+2 \times T d}{I d+O d} f_{r} N_{b}
$$

Based the data sheet of the bearing 7C55MP4017 used in the experiments of this paper, $N_{b}$ is $8 ; I d$ is $20 \mathrm{~mm}$; $O d$ is 47 $\mathrm{mm}$; $T d$ is measured at $2.6 \mathrm{~mm}$. If the shaft rotating frequency $f_{r}$ is constant at $10 \mathrm{~Hz}$ and $f_{1}$ is $60 \mathrm{~Hz}$, from (1) and (3), $F_{\text {outer }}$ are about $30 \mathrm{~Hz}, 90 \mathrm{~Hz}$, and $120 \mathrm{~Hz}, \ldots$, which are the characteristic frequencies of the outer-race bearing fault in the stator current signals. Based on the same analysis, $F_{\text {inner }}$ are about $20 \mathrm{~Hz}, 100 \mathrm{~Hz}$, and $120 \mathrm{~Hz}, \ldots$, which are the characteristic frequencies of the inner-race bearing fault in the stator current signals.

\section{THE PROPOSED PSD ANALYSIS-BASED METHOD}

Based on (1)-(4), the characteristic frequencies, $F_{\text {outer }}$ and $F_{\text {inner, }}$ of the outer-race and inner-race bearing faults, respectively, depend on $f_{r}$, i.e., the variable shaft rotating frequency of the WTG. As mentioned in [7], if a wind turbine rotates at a constant speed, the classical PSD analysis could identify a bearing fault effectively based on its characteristic frequency. Therefore, if the stator current signals are preprocessed such that the variable rotating frequency of the wind turbine is normalized to a fixed value, then the classical PSD analysis can be used to identify the outer-race bearing fault for a variable-speed wind turbine.

Define $\omega_{1}$ the discrete angular characteristic frequency of the outer-race bearing fault in the sampled data and $f_{s}$ the sampling frequency of the stator current and assume $f_{\text {fault }}=$ $g\left(f_{r}\right)$, i.e., $f_{\text {fault }}\left(F_{\text {outer }}\right.$ or $\left.F_{\text {inner }}\right)$ is a function of the shaft rotating frequency $f_{r}$, the relationship among $g\left(f_{r}\right), f_{s}$, and $\omega_{1}$ can be written as:

$$
\frac{\omega_{1}}{2 \pi}=\frac{g\left(f_{r}\right)}{f_{s}}
$$




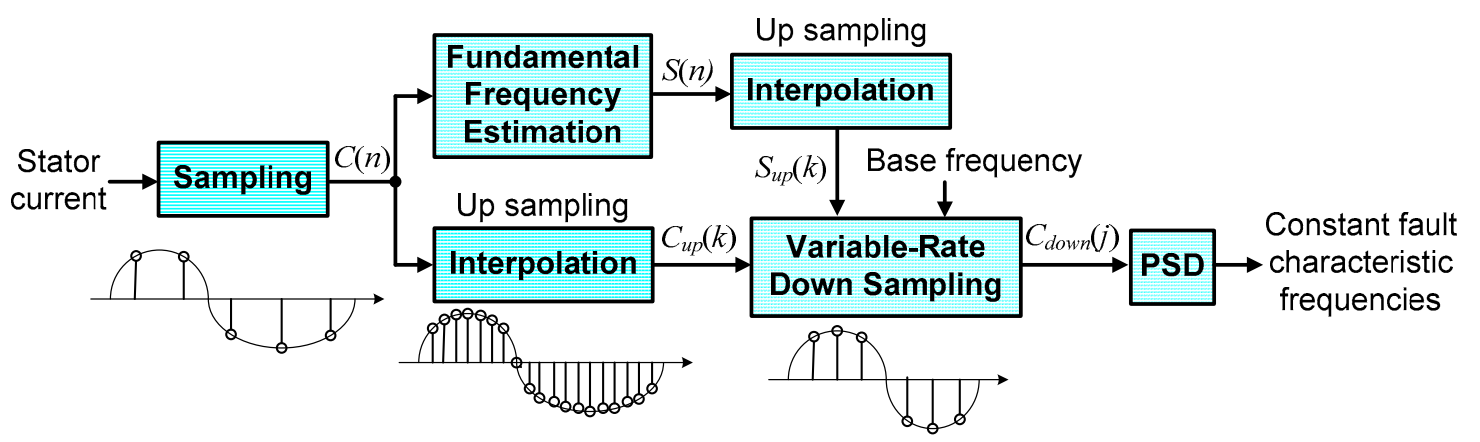

Fig. 2. The schematic diagram of the propose method.

where $\omega_{1}$ is expected to be constant for the PSD analysis. Therefore, if the sampling frequency $f_{s}$ is changed continuously with $f_{r}$ to make the right-hand side of (7) constant, $\omega_{1}$ will be constant. A method is proposed to preprocess the current samples of the WTG to obtain a constant $\omega_{1}$, which is shown in Fig. 2 and implemented in the following steps.

1) Estimate the fundamental frequency $f_{1}$ of the nonstationary stator current signal $C(n)$ of a WTG by using a phase lock loop (PLL) method; the result is $S(n)$, where $n$ $=1,2,3, \ldots, N$ and $N$ is the length of the stator current signal record;

2) Up sample or interpolate the stator current signal $C(n)$ and its fundamental frequency $S(n)$ by an up sampling ratio of $M$; the results are $C_{u p}(k)$ and $S_{u p}(k)$, where k $=1,2$, $3, \ldots, M \times N$

3) Choose the base frequency $f_{b}$ and the base value of the down sampling ratio $L$;

4) Down sample $C_{u p}(k)$ by a variable down sampling ratio of $L \cdot f_{b} / S_{u p}(k-1)$; the result is $C_{\text {down }}(j)$, where $j=1,2,3$, $\ldots, J$ and $J$ is determined by $M, N$, and $L$;

5) Calculate the classical PSD of the preprocessed stator current samples $C_{\text {down }}(j)$, whose fundamental frequency is now a constant value $f_{b}$.

By using the proposed method, the characteristic frequencies $F_{\text {outer }}$ and $F_{\text {inner }}$ become constant values in the PSD of $C_{\text {down }}(j)$ and can be used as a signature to clearly identify and quantify the outer-race and inner-race bearing faults, respectively. In the proposed method, the value of $L$ should be chosen based on two criteria. First, $L$ should be large enough to eliminate the quantization error due to the integral down sampling ratio. Second, $L$ should be small enough to guarantee that the result of the down sampled frequency is greater than twice the characteristic frequency of the outer-race or inner-race bearing fault.

\section{EXPERIMENTAL RESULTS}

A 160-W Southwest Windpower Air Breeze WTG is used in the experiments, as shown in Fig. 3. The generator has six pole pairs. The testing bearings are located between the rotors of the turbine and the generator and are pretreated

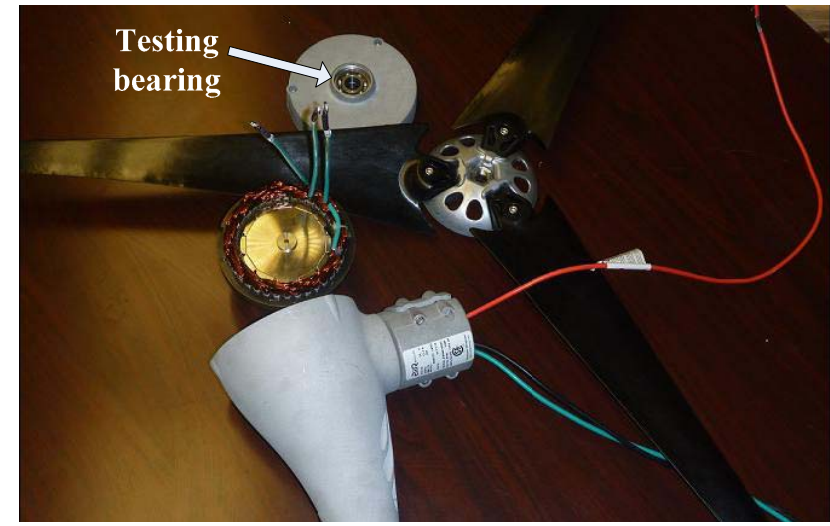

Fig. 3. The testing WTG.

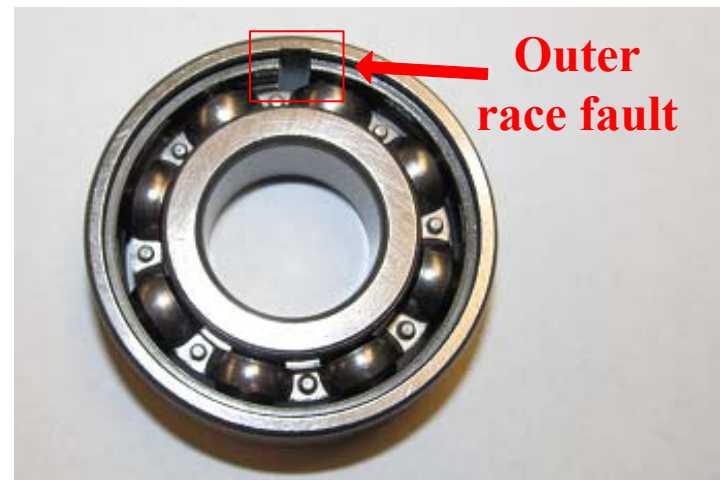

Fig. 4. The testing bearing with an outer-race fault.

by creating a defect at the outer-race and inner-race, as shown in Fig. 4 and Fig. 5, respectively. The WTG with the pretreated bearing is operated in a wind tunnel, as shown in Fig. 6, which can provide controllable wind with the speed from 0 to $10 \mathrm{~m} / \mathrm{s}$. In the experiments, the speed of the fan of the wind tunnel is varied to generate variable wind speed in the wind tunnel. One phase stator current of the WTG is recorded via a Fluke current clamp and National Instrument data acquisition system at a sampling rate of $10 \mathrm{kHz}$. The 


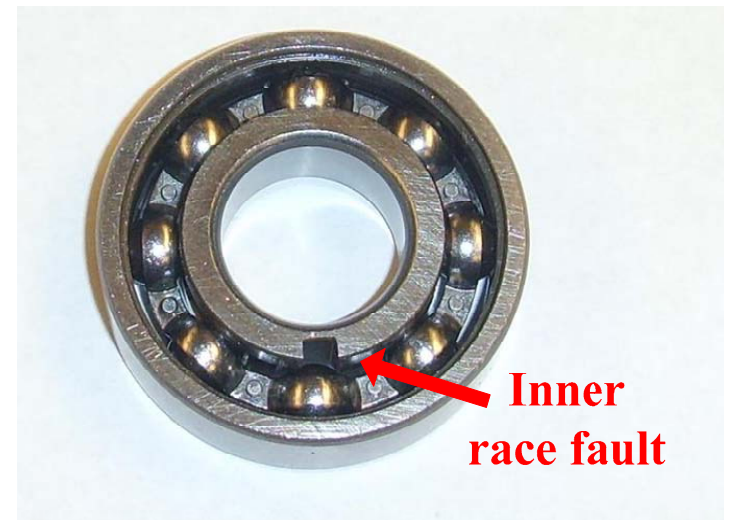

Fig. 5. The testing bearing with an inner-race fault.

current samples are acquired by the LabView software, and then sent to a lab computer. The length of the record is $210 \mathrm{~s}$.

Fig. 7 shows the variable shaft rotating speeds of the WTG with the healthy and outer-race and inner-race faulted bearings, where the fan speed varies in the range of $24 \mathrm{~Hz}$ to $29 \mathrm{~Hz}$.

Fig. 8 compares the PSD of the stator currents for the WTG with the healthy and outer-race faulted bearings by using the proposed method. The base frequency $f_{b}$ is chosen to be $60 \mathrm{~Hz}$ and the base value of the down sampling ratio $L$

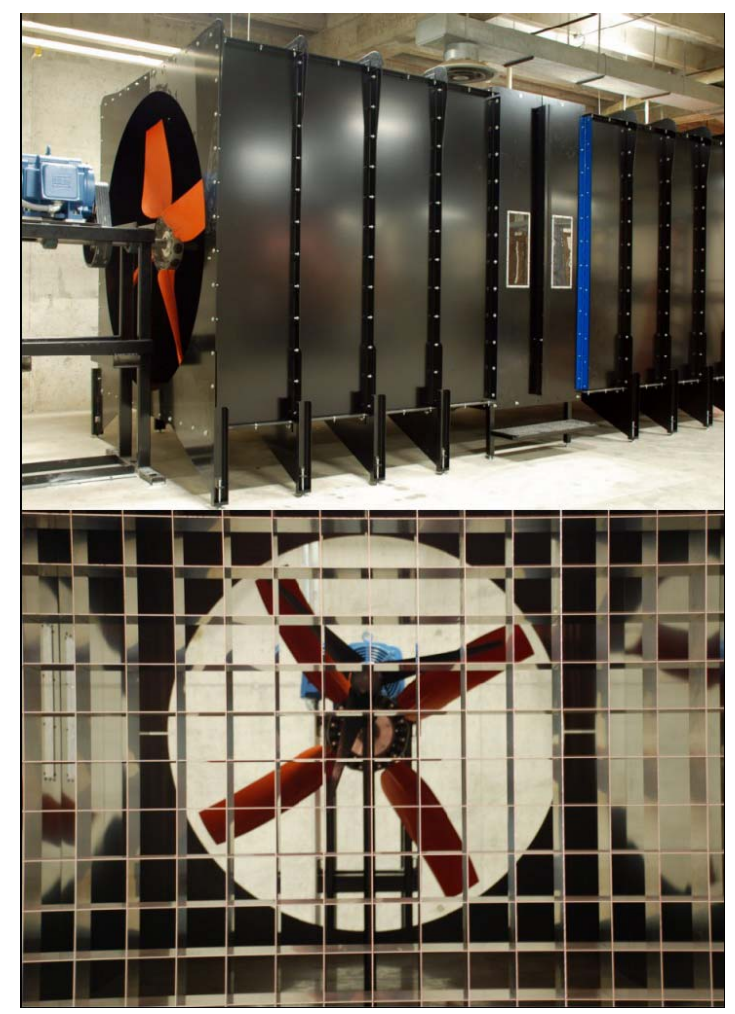

Figure 6. The wind tunnel with the testing WTG.

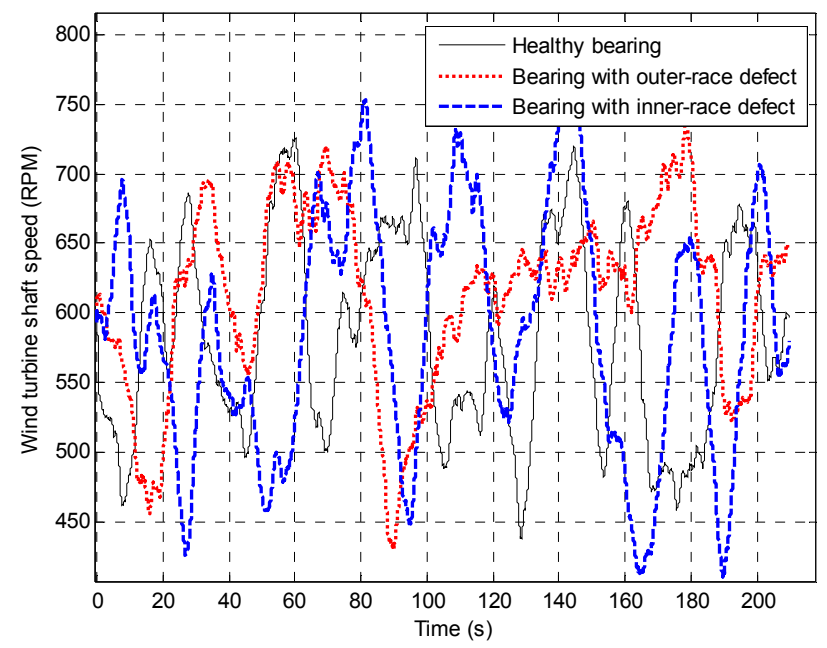

Figure 7. The testing bearing with an inner-race fault.

is 50. As shown in Fig. 8, an excitation appears in the stator current PSD at a fixed frequency of about $30 \mathrm{~Hz}$ in the faulted bearing case. This characteristic frequency of the outer-race bearing fault during the variable speed operation is the same as the first one calculated in Section II of the paper for a fixed shaft rotating speed of $10 \mathrm{~Hz}$. Thus, the magnitude of the stator current PSD at $30 \mathrm{~Hz}$ obtained from the proposed method is an effective index for the outer-race bearing fault detection.

Fig. 9 compares the PSD of the stator currents by directly using the classical Fast Fourier Transform (FFT)-based PSD method; no characteristic frequency is observed for the faulted bearing case. Due to variable rotating speeds of the WTG and the subtle excitation energy of bearing faults in the stator current, the classical PSD method fails to detect the variable characteristic frequencies of the bearing fault.

Fig. 10 compares the PSD of the stator currents for the WTG with the healthy and inner-race faulted bearings by using the proposed method with the same base frequency $f_{b}$ and base value of the down sampling ratio $L$ as in Figs. 8 and 9. As shown in Fig. 10, an excitation appears in the stator current PSD at a fixed frequency of about $20 \mathrm{~Hz}$ in the faulted bearing case. This fault characteristic frequency of the inner-race bearing faults during the variable speed operation is the same as the first one calculated in Section II of the paper for a fixed shaft rotating speed of $10 \mathrm{~Hz}$. Thus, the magnitude of the stator current PSD at $20 \mathrm{~Hz}$ obtained from the proposed method is an effective index for the innerrace bearing fault detection. Fig. 11 compares the PSD of the stator currents by directly using the classical FFT-based PSD method; again, no characteristic frequency is observed for the faulted bearing case.

\section{CONCLUSIONS}

A novel PSD analysis-based method has been developed for bearing fault detection of variable-speed direct-drive wind turbines using generator stator current measurements. 


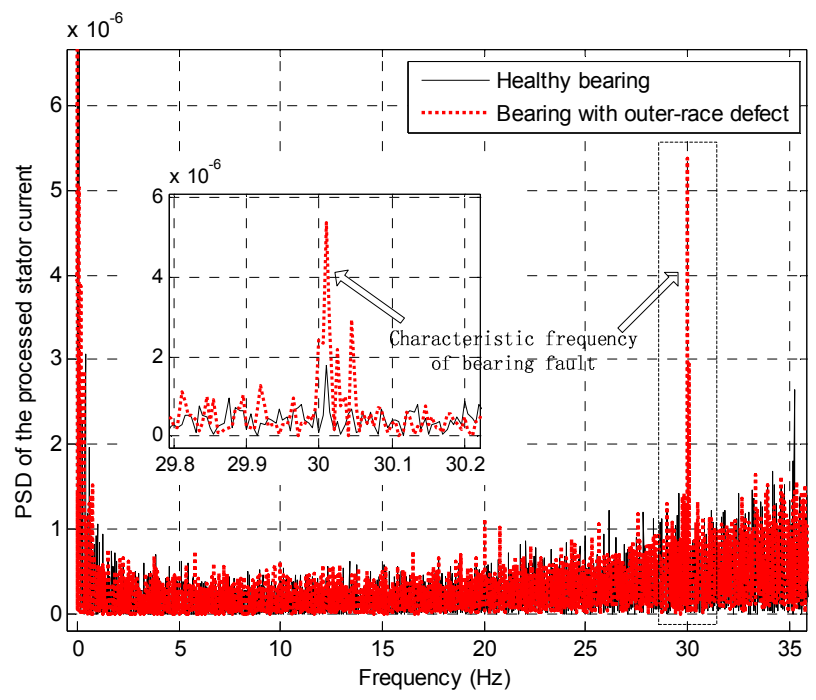

Figure 8. Comparison of the PSD of the stator currents for the WTG with the healthy and outer-race faulted bearings by using the proposed method.

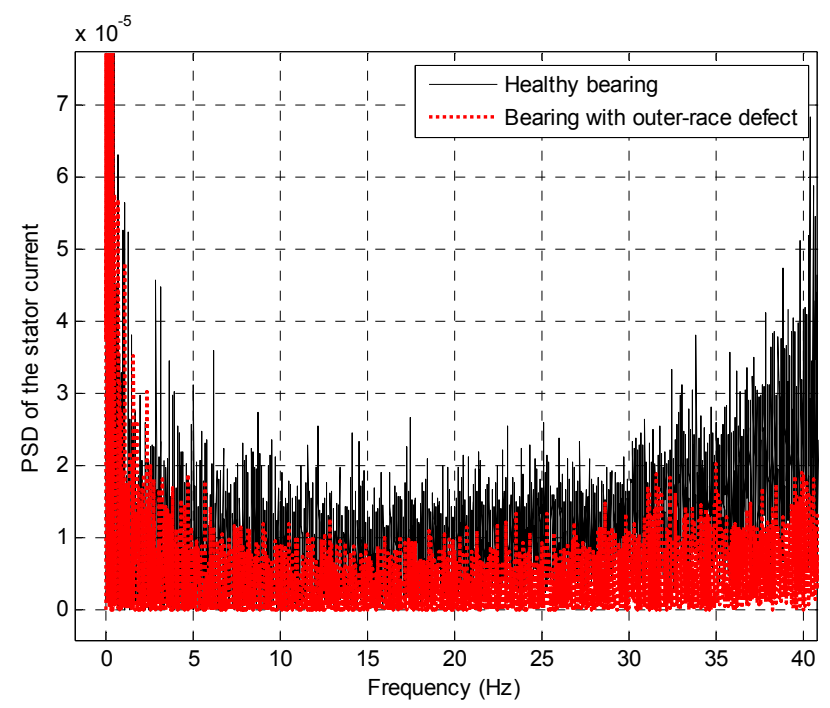

Figure 9. Comparison of the PSD of the stator currents for the WTG with the healthy and outer-race faulted bearings by using the classical FFTbased PSD method.

Appropriate up-sampling and down-sampling algorithms have been designed in the proposed method to convert the variable characteristic frequencies of the bearing faults to a fixed frequency according to the estimated rotating speed of the WTG. Consequently, bearing fault excitations can be clearly identified and quantified by using the results of stator current PSD. Experimental studies for a direct-drive WTG have shown that the proposed method can effectively identify outer-race and inner-race bearing faults for the WTG operating in variable speed conditions. The proposed method can also be applied for detection of other types of faults with characteristic frequencies in WTGs.

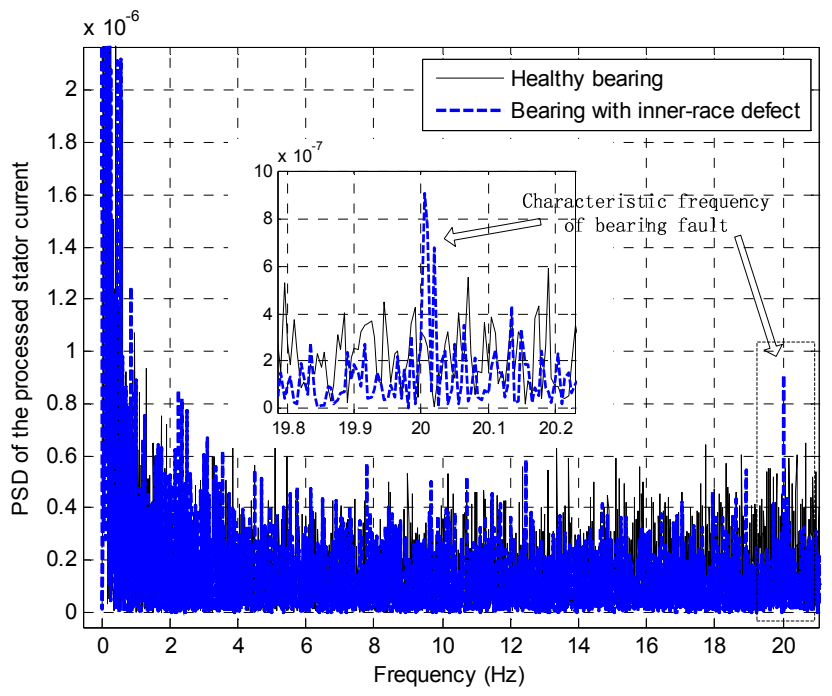

Figure 10. Comparison of the PSD of the stator currents for the WTG with the healthy and inner-race faulted bearings by using the proposed method.

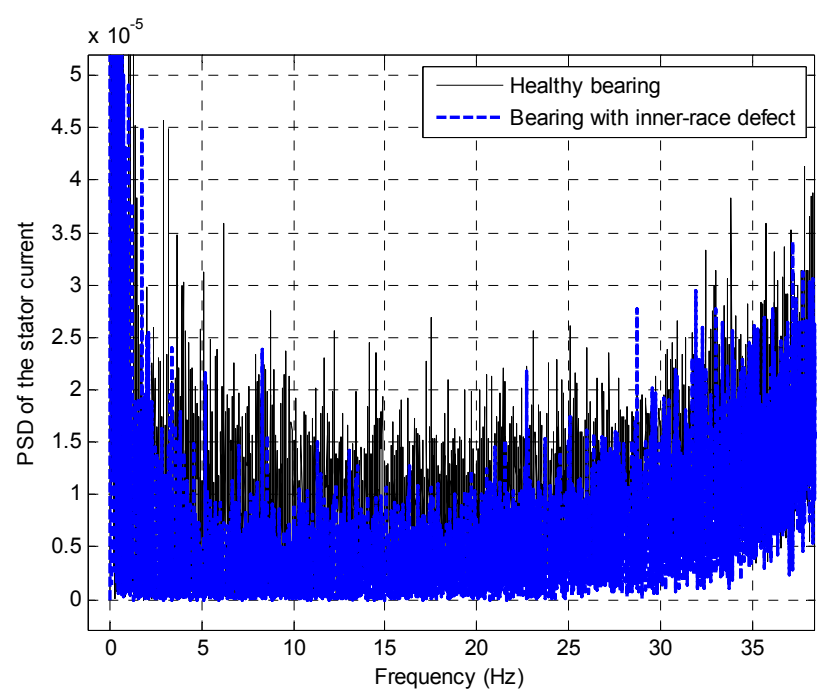

Figure 11. Comparison of the PSD of the stator currents for the WTG with the healthy and inner-race faulted bearings by using the classical FFT-based PSD method.

\section{REFERENCES}

[1] Y. Amirat, V. Choqueuse, M. E. H. Benbouzid, and J. F. Charpentier, "Bearing fault detection in DFIG-based wind turbines using the first intrinsic mode function," in Proc. XIX International Conference on Electrical Machines, Rome, Italy, 2010.

[2] W. Zhou, T. G. Habetler, and R. G. Harley, "Bearing condition monitoring methods for electric machines: A general review," in Proc. 6th IEEE International Symposium on Diagnostics for Electric Machines, Power Electronics and Drives, Poland, Sept. 6-8, 2007, pp. 3-6.

[3] M. Blodt, P. Granjon, B. Raison, and G. Rostaing, "Models for bearing damage detection in induction motors using stator current monitoring," IEEE Trans. Industrial Electronics, vol. 55, no. 4, pp. 1813-1822, Apr. 2008. 
[4] R. Ramlau and J. Niebsch, "Imbalance estimation without test masses for wind turbines," Journal of Solar Energy Engineering, vol. 131, no. 1, Feb. 2009

[5] S. J. Watson, B. J. Xiang, W. Yang, P. J. Tavner, and C. J. Crabtree, "Condition monitoring of the power output of wind turbine generators using wavelets," IEEE Trans. Energy Conversion, vol. 25, no. 3, pp. 715-721, Sept. 2010.

[6] R. R. Schoen, T. G. Habetler, F. Kamran, and R.G. Bartfield, "Motor bearing damage detection using stator current monitoring," IEEE Trans. Industry Applications, vol. 31, pp. 1274-1279, Nov./Dec. 1995.

[7] B. Trajin, J. Regnier, and J. Faucher, "Bearing fault indicator in induction machine using stator current spectral analysis," in Proc. 4th IET Conference on Power Electronics, Machines and Drives, York, U.K., Apr. 2008, pp. 592-596.
[8] K. Teotrakool, M. J. Devaney, and L. Eren, "Adjustable-speed drive bearing-fault detection via wavelet packet decomposition," IEEE Trans. Instrumentation and Measurement, vol. 58, no. 8, pp. 2747 2754, Aug. 2009.

[9] C. Li and G.Yu, "A new statistical model for rolling element bearing fault signals based on Alpha-stable distribution," in Proc. Second International Conference on Computer Modeling and Simulation, Shenzhen, China, Jan. 22-24, 2010, pp. 386-390.

[10] R. A. Gupta, A. K. Wadhwani, S. R. Kapoor, "Early Estimation of Faults in Induction Motors Using Symbolic Dynamic-Based Analysis of Stator Current Samples," IEEE Trans. Energy Conversion, vol. 26, no. 1, pp. 102-114, Mar. 2011.

[11] R. L. Schiltz, "Forcing frequency identification of rolling element bearings," Sound and Vibration, vol. 24, no. 5, pp. 16-19, May 1990. 